think that the shock of a skilfully and rapidly parformed/pyrexial type, but are non-paroxysmal in nature and 3aparotomy is greater than that produced by injection when unamenable to quinine.

sufficient force is used to disengage the invagination. The 1 . The first of these is "simple ardent fever" or febricula, dangers and uncertainty of inflation and injection have been well shown by Lawford Knaggs ${ }^{1}$ and Mortimer. ${ }^{2}$ I am convinced that a wider appreciation of the dangers of injection and the success of early laparotomy will do much to reduce the mortality of the disease; and this, Sirs, I must ask you to sccept as my excuse for having had the temerity to question the views you have expressed.

I am, Sirs, yours faithfully,

Westbourne-terrace, W., Feb. 25th, 1895 . E. W. ROUGHTON.

** We print Mr. Ronghton's interesting letter with cleasure, but we still consider that our recommendation of a trial of the injection of air or fluid in these cases previously to abdominal section, where the symptoms have been in existence less than forty-eight hours, a sound one. In careful Gands these measures are comparatively unattended with risk, and are likely to be successful in a majority of cases treated within the specified time. We do not recommend that operation should be deferred after an unsuccessfal attempt has been made at reduction by other means, no matter how recent the symptoms may be.-ED. L.

\title{
THE FEVERS OF INDIA AND THE MEDITERRANEAN.
}

To the Editors of THE LANCET.

SRRS, - I bave read with much interest in THE LANCET of Jan. 19th last the Presidential Address in Medicine and Pathology at the Indian Medical Congress by Surgeon-Lieutenant-Colonel Crombie, I.M.S. In attempting to classify the "fevers of India" into specific groups and varieties he has grappled with a question which for years has been a stum"bling block in our official nomenclature of diseases, not only in India but in the Mediterranean and elsewhere. In this momenclature we find: 1. Malarial fevers, subdivided into $r(a)$ intermittent fever; $(b)$ remittent fever; and $(c)$ malarial cachexia; a subdivision founded in the two former cases on a single clinical characteristic not confined to any individual specific fever. 2. Fnteric fever well known and carefully befined, but having a subheading termed "typho-malarial fever," a combination of malarial and enteric fever. 3. Simple continued fever defined as "continuous fever, having no obvious distinguishing character." Paludism, which has now been fairly proved to be the result of Laveran's hæmatophyllum, is the condition at present commonly accepted as true malarial fever. According to the variety, quantity, or quality of the virus in given cases, so rit is believed the pyrexial curve becomes intermittent, remittent, or continuously high, but the disease is of a paroxysmal nature and amenable to quinine. Malarial cachexia is accepted as the result of the prolonged action on the body tissues of the same parasite. Enteric fever, though a well defined specific fever, frequently runs a most remittent course, while cases of tuberculous suppuration may be most intermittent in type, yet no one would dream of diagnosing either of these pyrexial conditions as "malarial fevers." The greater part, however, of the remaining fevers of tropical and subtropical regions which have not yet been definitely named must, if of a remittent or intermittent character, be classified either with paluđism, as malarial fevers, or as simple continued fevers, however many obvious distinguishing charactors they may possess. Surgeon-Lieutenant-Colonel Crombie -deals with four such types of non-malarial fevers occurring in India, two of which he ventures to think are specific forms. Three types are especially interesting to medical officers serving in Malta, as very analogous forms of fever exist and are endemic in that and other places in the Mediterranean, which for want of better names are in the army with sad irony tiagnosed as "simple continued fever" in spite of most obvious distinguishing characters and a difference in duration of any time between two and 200 days' stay in hospital. Paludism these cases certainly are not, as this form of fever is not endemic in Malta, and occurs only in the form of celapses in men who have previously suffered from the disease in Cyprus, India, Mauritios, or elsewhere. They may, howEver, be intermittent, remittent, or continuously high in short fever of from three to six days' duration met with in almost every country, and doubtless specific. 2. Next there is an acute fever of about fourteen days' duration, similar to the form termed "Calcutta or Bombay fever" by SurgeonLieutenant-Colonel Crombie. Though diagnosed simple continued fever, it is usually said to be abortive enteric, and in pyrexial curve it resembles a case of enteric fever telescoped into a fortnight. It is, however, devoid of any other clinical resemblance and has every appearance of being a distinct fever. To my knowledge it occurs in Malta, Gibraltar, and Egypt. 3. Thirdly, there is a low form of fever varying between $99^{\circ}$ and $101.5^{\circ} \mathrm{F}$. (when taken morning and evening), never being normal, and occasionally remaining for trom four to six weeks continuonsly between $99^{\circ}$ and $100^{\circ}$. This is generally associated only with anorexia, anæmia, and debility, but may also be combined with neuralgic or rheumatic symptoms. It is not common, and is generally merged into the next class of fevers. Whether it is similar to the "low fever" of Surgeon. Lieutenant-Colonel Crombie and a specific disease I cannot say. 4. Lastly, there is the fever known as Malta, Rock, and Mediterranean fever, pseudo-typhoid, fæco-malaria, \&c. It has an irregular course, an indefinite duration, may vary in pyrexial type, but is characterised more especially by its lengtb, tendency to relapse, constipation, anæmia, and rheumatic and neuralgic complications. In severe cases the temperature becomes continuously high, and, combined as they then are with a tendency to the "typhoid state," lead to a similarity in clinical characters to enteric fever. Othe cases may in pyrexial curve almost seem to be enteric fever, followed by five or six relapses. The majority, however, are clearly and definitely distinct, and in the few fatal cases (under 2 per cent.) not only are Peyer's patches unaffected but a characteristic micrococcus, capable of producing a similar fever in monkeys, replaces Eberth's bacillus. ' Certain cases, again, become intermittent in type, but nonparoxysmal, and resemble the hectic pyrexia of phthisis. Cases of this fever, though diagnosed as simple continued fever in the army, are by the naval and civilian medical men diagnosed as "remittent fever," and together with remittent paludism, and under the heading of malorial fevers.

The time appears to bave come when malarial fevers and malarial cachexia should be classified as one group, nnder such a name as paludism, and be recognised as the results on the body tissues of Laveran's amobre, any necessary sub. divisions being based on more scientific data than one clinical feature common to many fevers. Let "typho. malarial fever" be also abolished, and such conditions be diagnosed according to the disease at the time the more serious, as would be done in the event of enteric fever occurring in a patient already suffering from constitational syphilis. This will leave a number of fevers at present termed "continued" withont definite names, but these forms will, on account of their obvious distinguishing characters, soon find names when the vague terms "inter mittent " and "remittent" fever are abolished. More accurate clinical observation and epidemiological and biological research must soon settle the question, as has been done in the cases of typhas, enteric, and paludic fevers, for every year the circle is closing in. In conclusion, let us hope with Surgeon-Lieutenant-Colonel Crombie, that England wil not yield the palm of discovery to Germany or France in this matter.-I am, Sirs, yours faithfully,

$$
\begin{aligned}
& \text { Malta Jan. 28th, } 1895 . \quad \text { M. LoUIs HUGHES, } \\
& \text { Surgeon-Captain, A.M.S. }
\end{aligned}
$$

\section{THE TREATMENT OF INFLUENZA.}

\section{To the Editors of THE LANCET.}

SIRS, -As we are in the midst of another widely spread epidemic of influenza I should like to call attention to the routine and somewhat reckless use of such drugs as salicin and antipyrin, which I observe is still common in the treatment of this malady. After between four and fire years' experience and observations of the effects of various methods of treating influenza I have been unable to resist the con. viction that these drugs, while they doubtless relieve some of the most distressing early symptoms, possess no resl

The Laycer, Dec. 12th, 1892, and Annales de l'Institut Pasteur, August, 1893 
antitoxic influence over this affection, and not only leave the patient exposed to all the serious after-effects of the influenzal intoxication, but even render him more susceptible to some of them. The drugs, which I notice are now often prescribed in combination, are all the more dangerous, because their immediate effects are usually pleasant both to the patient and the practitioner. The patient is pleased to have the more painful symptoms speedily relieved and the practitioner is pleased to have the credit of being able to relieve them. But patients who have been thus treated of ten have a tedious convalescence, and are very subject to recurrent attacks of cardiac debility as well as to other serious sequelæ. I have often been strack with the pale, exhausted, worn, and shrunken aspect of some of these "convalescents." On the other band, both clinical and experimental evidence point to quinine as a true antitoxin in influenza. No doubt many persons complain much of certain disagreeable $t$ ffects which fall doses of quinine occasionally produce; but these should, in most cases, be looked upon as a small evil compared with the grave after-effects which are especially apt to occar when quinine has not been adequately or suitably sdministered. In malarious countries no medical practitioner would feel justified in withholding quinine because of any supposed "intolerance" of that remedy. I have elsewhere pointed out how much better quinine is tolerated by many persons, and how much more beneficial its action appears to be when given in combination with an alkaline saline; bnt my object now is to point out that the use of such drugs as salicin and antipyrin should be restricted to two or three doses given simply for the relief of the pains attending the onset of the disease ; that they are harmful if given freely and as a matter of routine; and that we should rely mainly upon quinine as a proved antitozic agent in this disease. The present widely diffused outbreak on the cessation of the protracted frost seems to point to the sudden mobilisation of the imprisoned bacilli, or possibly to the snspension of their infective activity during the prevalence of the rery low temperature.

I am, Sirs, your obedient servant,

I. BURNEY YEo, M.D., F.R.C.P.

Professor of Clinical Therapeuties in King's College. Herfford-street, Mayfair, Feb. 25th, 1895.

\section{"THE ABSENCE OF SUGAR FROM NORMAL} URINE PROVED BY A NEW AND SIMPLE METHOD."

To the Editors of THE LANCET.

Sins, - The only comment necessary upon Sir George Johnson's last letter is to remark that the words following Dr. Halliburton's statement about there being enough to convince the impartial observer that a small quantity of glocose is obtainable from normal urine did not stand in the position of being held back by me, inasmach as the text in full had been the previous week before your readers. Passing to Dr. Halliburton's letter, I am asked to amplify my position with respect to the detection of alcohol by the chromic acid test. This matter was incidentally introduced in a quotation from the Guy's Hospital Reports for 1876 detailing the application of the fermentation test at a meeting of the Royal Medical and Chirurgical Society in 1875. It is perfectly true, as stated by Dr. Halliburton, that a number of volatile organic principles react with chromic acid in the same manner as alcohol ; but I doubt not that Dr. Halliburton will admit that to get the reaction one or other of these principles must be present, and that for their presence there must be a source for them. Now, the product submitted to the action of the fermentation test consisted of an aqueous solution of the extracted sugar obtained by liberation from its lead compound, and the solution had been frevious to employment concentrated by evaporation in an open capsule. Hence, if it had been possible-and I contend it was not-for one or other of these principles to be present it would have been dissipated in the process of evaporation, leaving the alcohol generated by fermentation as the only agent permissible to look to for the reaction that was observed. Dr. Halliburton's invitation to enter upon a discrasion of the question of kreatinine I am not tempted to accept. I am, Sirs, yours faithfully,

Grassenor-street, Feb. 27th, 1895 .

F. W. PAVY.

* This correspondence must now cease. If none of the parties to it have exactly convinced each other, they have made sufficiently clear the points at issue between them, and it is possible that the debate between authorities so well qualified to hold strong opinions on the subject will stimulate others to assist the profession at arriving at a definite conclusion on a very interesting point.-ED. $\mathrm{L}$.

\section{"THE GENERAL MEDICAL COUNCIL AND THE OBSTETRICAL SOCIETY." \\ To the Editors of THE LANCET.}

SIRS,--Dr. Lovell Drage has hitherto written so ably orx the question of midwives' registration that I was disappointed on reading his letter to find only a réchauffé of the old stocks arguments. However, the very pertinacity of their appearance demands a categorical answer. We are apparently now all agreed that something must be done, but to be effectua what is done must be done with the consent of the great majority of the profession, and must bave its cordial support, Again, we are mostly agreed that proper education and efficient control are the points aimed at. The Obstetrical Society have endeavoured to fulfil the first condition, but are absolutely helpless as regards the second, and it is with a view to obtaining this power of control that registration is asked for. I admit that the present method of granting diplomas by the Obstetrical Society has great drawbacks, but accept it on the principle that half a loaf is better than none. It would be surprising if no fault or omission could be found in the regulations for an examination, but in the instance quoted the society have evidently very properly shown their appreciation of the defect by the issue of the circular mentioned. Dr. Drage complains that certain representations on the subject have been unheeded. I thought they were old and well-known friends. The first statement as to mortality statistics is weakened by the want of a fuls: knowledge of all the factors, without which any figures become little more than decorations for a discussion. We want to know the rates before there was State control. We want the rates both in those cases attended by registerec midwives and in those attended by uneducated midwives. We at least should know the proportion of cases attended by the State-controlled midwives, especially as we are told in the next paragraph that the system has not resulted in removing the unqualified practitioner. It must be remembered that it is not only or chiefly mortality-rate, but sickness. rate, both direct and indirect, that we have to consider Registration, I admit, will not immediately or absolutely remove the unregistered practitioner. We are reluctant to interfere with vested interesis, so the continuance and maintenance of untrained midwives constitute one of those difficulties that are inseparable from the establishment of a nev.n systera. How long it will last and how much it will flourish will depend on the support which any new system receives. from the profession whose daty it will be to educate the people to an appreciation of their danger and the ways ce safety ; therefore am I most anxious that some means may be found of settling this rexed question. That midwives do not send for the surgeon for the repair of the perineum must be a fault of education and training, but one that may apply to not a few qualified medical men in large practice ; but, even admitting this fault, the mid wives at any rate know" the danger, and are in a better position to rectify it than a. nurse withont any education. Secondly, it is objected that. of the 2000 diplomates of the Obstetrical Society few are found practising among the poor except as the employes of institutions or charities. This is surely the best thing that. could be wished for; here we have the desired condition of control, and very efficient it is, and what, may I ask, could these: charities have done without the much-reviled society to selects efficient midwives for them to employ? It is doubtfil whether a trained midwife in a country district would be: able to earn a sufficient competence to make it worth ber" while to go through a comparatively expensive training. And I believe that a solution will be found in the village nursing: associations that are now coming into existence in so many? places, and which guarantee the expenses of a nurse who is. both oistrict nurse and midwife, and I trust that the time: may come when the guardians of the poor may see fit to act. in the same capacity as the nursing associations. But we sball never get out of the difficulty if we wait for the perfection that is shadowed in Dr. Drage's third statement, that midwives shall not be certified because "certified midwives have been found gailty of criminal practices."; surely not our own or any other profession or any class of society in this 